\title{
Linking meters and markets: Roles and incentives to support a flexible demand side
}

\author{
Katz, Jonas
}

Published in:

Utilities Policy

Link to article, DOI:

10.1016/j.jup.2014.08.003

Publication date:

2014

Document Version

Early version, also known as pre-print

Link back to DTU Orbit

Citation (APA):

Katz, J. (2014). Linking meters and markets: Roles and incentives to support a flexible demand side. Utilities Policy, 31, 74-84. https://doi.org/10.1016/j.jup.2014.08.003

\section{General rights}

Copyright and moral rights for the publications made accessible in the public portal are retained by the authors and/or other copyright owners and it is a condition of accessing publications that users recognise and abide by the legal requirements associated with these rights.

- Users may download and print one copy of any publication from the public portal for the purpose of private study or research.

- You may not further distribute the material or use it for any profit-making activity or commercial gain

- You may freely distribute the URL identifying the publication in the public portal

If you believe that this document breaches copyright please contact us providing details, and we will remove access to the work immediately and investigate your claim 


\title{
Linking meters and markets: Roles and incentives to support a flexible demand side
}

\author{
Jonas Katz \\ Technical University of Denmark, Department of Management Engineering, Energy Systems Analysis, \\ Risø Campus, Frederiksborgvej 399, 4000 Roskilde, Denmark \\ Phone: +4524658855
}

\begin{abstract}
Present trends in the development of electricity systems are expected to generate a growing need for flexibility in decentralised resources, including demand response. In order to enable decentralised actors to create value, the organisation of markets and incentives should incorporate these new participants. The roll-out of smart metering to electricity consumers is an important precondition to establishing a flexible demand side and will provide essential information flows. On the basis of current incentive structures and related risks, however, the pass-through of information and value from wholesale market participants to the demand side is mostly infeasible, resulting in flexibility tasks being aggregated and delegated to balancing responsible wholesale traders. This analysis focuses on whether current incentives and roles are appropriate and where the design could be improved to establish a flexible demand side with a particular focus on the Danish case. Design-related barriers are identified that affect expected value, associated risks, and the distribution of responsibilities. This serves as a basis to define policy options in the context of Nordic electricity markets.
\end{abstract}

Keywords: demand response, smart-meter roll-out, decentralised resources, distributed generation, electricity market-roles, product design, flexibility

\section{Introduction}

Policy-makers intend to cure the missing information transfer between the demand side and wholesale markets by rolling out smart metering to all or most customers. Arguments for establishing this kind of infrastructure are based on socio-economic calculations that show substantial benefits induced by flexible demand-side resources (e.g., Danish Energy Agency, 2013, Energinet.dk, 2013, for Denmark). However, such findings also rely on significant adoption rates.

Email address: jokat@dtu.dk (Jonas Katz) 
At the moment many barriers, mainly regulatory and institutional, still exclude decentralised resources from the informational flows about flexibility supply and demand (e.g., Greening, 2010).

Currently, with market products generating only weak incentives, combined with their risk profiles it remains an open question whether adoption will take place at expected rates and if economic projections are justified. The present distribution of responsibilities for handling flexibility suggests the need for some adjustment.

Considering the Danish situation, the existing market places for flexibility are reviewed from the perspective of decentralised resources, including both demand response and distributed generation.

The analysis focuses not so much on the economic value of flexibility and the underlying incentive to bring it to the market. Instead, the focus lies on how flexibility trades and whether the form of products and the organisation of markets fit with the characteristics of demand-side flexibility. The reasoning is that while the demand for flexibility and its value can be expected to increase with growing shares of intermittent production, it is of central importance that information about the rise in value is in a form that creates demand-side incentives.

The next section lays out the scope and research interest in more detail. It points out trends that suggest a growing importance of flexibility from decentralised resources and describes the approach taken towards barriers to demand-side flexibility. A clear distinction is drawn between barriers caused by the underlying market structure and additional barriers introduced by regulation and design. Hereafter the major design-related barriers as well as options to address them in favour of small-scale demand-side actors are presented and discussed.

\section{Drivers for decentralised flexibility}

\subsection{A growing demand for flexible resources}

The necessity of providing flexibility to the system originates from reliability requirements. Securing system balance and power quality at all times are basic preconditions to the operation of electricity systems. In a liberalised electricity market these requirements establish the demand side in a market for flexibility.

As reliability is both a long-term and a short-term task, so is the provision of flexibility. In the long-term the reliability or system adequacy requirement traditionally meant providing sufficient production and transmission capacity to serve demand at all times (ENTSO-E, 2004). Here flexibility is seen as the ability to handle fluctuations in demand (see also Nicolosi, 2010). With recent developments in intermittent production, adequacy increasingly must to take into account variability of production.

In the short term reliability translates into security requirements within an otherwise adequate system. In particular, reserve requirements for outages and stochastic deviations are determining factors. Although electricity demand is subject to forecasting errors, these are comparatively small on an aggregated basis. Flexibility in the short term, therefore, is almost completely driven by the supply side of the system (Gül and Stenzel, 2005).

The demand for flexibility due to adequacy and security requirements thus depends very much on supply-side developments. In a broader sense, therefore, flexibility can be defined as changes in 
the behaviour of connected parties to accommodate system needs (Dansk Energi and Energinet.dk, 2012). As the supply side of electricity changes, so will the value of and the demand for flexibility. The development of variable renewable electricity production, accordingly, is expected to increase the demand for flexible capacity (Grohnheit et al., 2011).

\subsection{Declining availability of traditional flexibility providers}

Centralised thermal power plants are the most common providers of operational flexibility to the system at present. Due to low marginal costs of most renewable energies, conventional production technologies may experience lower utilisation rates. Combined with the overall price depressing effect (cp. Munksgaard and Morthorst, 2008), this reduces the feasibility of these traditional suppliers of flexibility.

Therefore, it can be expected that conventional sources of flexibility will become less available or, at least, more costly (cp. e.g., Droste-Franke et al., 2012, p. 63ff., for an analysis of German scenarios). Although there is an option of keeping them on-line to provide reliability services, this may result in substantial costs. Adding new flexibility resources should be considered.

Several flexibility options have been identified, ranging from grid extension to establishing storage and demand response (cp. BMU, 2012, Energinet.dk and Dansk Energi, 2012, Gül and Stenzel, 2005). Some of those are centralised options and others are more decentralised, that is, smaller in size and typically connected to lower voltage grids. A cost-efficient system should take advantage of and optimise among all available resources.

\subsection{Decentralisation of reliability management}

Building an electricity system with large shares of intermittent renewable production typically implies that the supply structure becomes more decentralised. Therefore regional and local grids may become challenged. As a result, reliability management requires either more grid capacity or more decentralised solutions (CIRED, 2013).

Currently, flexibility services are primarily managed by transmission-system operators. At the distribution level, reliability requirements traditionally have been covered by investments in new grid capacity. In a future system with increasing variable activity at the distribution level, building sufficient grid capacity may come at a significant cost and distribution-system operators may instead ask for flexibility services and seek to establish a more active management of such resources (Energinet.dk and Dansk Energi, 2012).

In addition to the specific challenges in distribution grids, various benefits have been identified and are expected to become effective when activating the flexibility of the demand side (see e.g., Albadi and El-Saadany, 2008, Andersen et al., 2006). Active demand response is expected to improve general market performance by reducing variability of prices and preventing market power (Kirschen, 2003, Hirst, 2001). It reduces the usage and investments in peak capacity and supports reliability (Strbac, 2008, Earle and Faruqui, 2006). At the same time, improved monitoring may lead to operational benefits to suppliers and grid companies (Faruqui et al., 2010).

Although developing a smart and flexible demand side is supported by research and acknowledged by policy-makers in countries with growing shares of renewable resources, including Denmark 
and Germany, the scale is an ongoing debate (see Lund et al., 2012). In particular the demandresponse potential from most household appliances may be limited. If individual transport and heating systems become electrified, however, the flexibility of such devices should be utilised actively in order to prevent severe reliability issues (Slootweg et al., 2011).

\subsection{Market structure and impacts of market design}

Many options already exist to activate flexible capacities on the demand side. In principle demand response and other decentralised resources also are able to participate in most if not all of the relevant markets (Hirst, 2002). The lack of smart metering installations is sometimes considered a major barrier to the utilisation of demand response (e.g., Kim and Shcherbakova, 2011). While this clearly is an important technical precondition, metering by itself is not sufficient to induce flexible demand.

In order to enable decentralised actors to create value, informational links between markets and customer meters should be established. The current information asymmetry in electricity markets to a great extent explains the inelasticity of demand (Stoft, 2002). It has been shown that customers respond to dynamic price information (Faruqui and Sergici, 2010), but even in the case of large-volume market participants (such as industrial customers) with advanced metering already installed, timely information about market conditions is only rarely passed-through.

Customers often prefer fixed rates to variable ones (for a survey amongst large Danish consumers, see Dansk Energi Analyse and Norenergi, 2005), and household customers may prefer stable prices as well (Costello, 2004). An astonishing finding is that only a small number of customers with real-time metering is actually bringing flexibility to the market (see Faruqui et al., 2014).

From a commercial point of view, three major reasons contribute to this situation. First, the expected value from response actions on existing markets is low. Second, even though studies claim to identify value created from demand response, it will always be subject to substantial risks. Third, demand-side actors are mostly not held responsible for their behaviour toward the system.

All of these three barriers may be perfectly good reasons, economically speaking, to refrain from implementing demand response in spite of smart metering installations. It would be clearly inefficient to employ demand response if the related costs for enabling automation equipment and information management are not competitive. Prevailing market risks add to the cost of demand response as well. Delegation of responsibility also makes economic sense due to economies of scale and benefits from portfolio aggregation.

These conditions are built into the basic structure of the market. They are based on the underlying economics of flexibility, on technological restrictions and costs, which are difficult to affect by policy-makers. While these structural barriers exist, they are most certainly not the only reasons for weak incentives and missing information flows (see Sorrell, 2004, for an analysis of barriers in the context of energy efficiency). There is a difference between the value that demand-side flexibility could add to the electricity system and the value reflected in market conditions and perceived on the demand side. Essentially, this difference can be attributed to imperfect information not addressed by market design. As shown below, the small size of the potential new flexibility resources and their location at the distribution-grid level play an important role in this regard. 
Table 1: Market structure and market-design impacts on flexible demand

\begin{tabular}{|c|c|c|}
\hline & Basic market structure & Market-design impacts \\
\hline Expected value & $\begin{array}{l}\text { Value based on: } \\
\qquad \begin{array}{l}\text { - Supply/demand balance } \\
\text { - Price-elasticity } \\
\text { - Technology } \\
\text { - Costs }\end{array}\end{array}$ & $\begin{array}{l}\text { Low perceived value due to: } \\
- \text { Imperfect information about location } \\
\text { of supply/demand } \\
\text { - Imperfect information about timing of } \\
\text { demand }\end{array}$ \\
\hline Risks & $\begin{array}{l}\text { Risks due to: } \\
\quad \text { - Price-dependent revenue } \\
\text { - Timing of response (availability) } \\
\text { - Greater technical risks (reliability) }\end{array}$ & $\begin{array}{l}\text { High perceived risks due to: } \\
\begin{array}{l}\text { - Difference between planning horizon } \\
\text { and trading lead times } \\
\text { - Penalties for non-availability } \\
\text { - Unsuitable hedging instruments }\end{array}\end{array}$ \\
\hline Responsibility & $\begin{array}{l}\text { Delegation due to: } \\
\quad-\text { Economies of scale } \\
\quad-\text { Efficiency gains from aggregation } \\
- \text { Specialisation }\end{array}$ & $\begin{array}{l}\text { Limited responsibility due to: } \\
\text { - Pooling requirements } \\
\text { - Defined information flows in market } \\
\text { model }\end{array}$ \\
\hline
\end{tabular}

Another distinct characteristic of decentralised flexibility resources is that their primary function is not to provide services to the electricity system. Therefore the planning horizon and availability for these services is different from traditional options. Market organisation and product design perfectly suited for centralised actors may imply additional uncertainties for small-scale actors (e.g., Cappers et al., 2012), although, they would not necessarily pose an additional risk to the system.

Accordingly, the distribution of responsibilities across the whole model of market roles is designed around a passive demand side. If predefined by legislation or market rules, however, delegation of responsibility may become a barrier to utilising decentralised resources in spite of potentially favourable economic incentives.

The market should take the structural characteristics of the demand side into account if its flexibility is to be developed as a resource option. In the following framework, to distinguish it from basic structural factors, market design refers to features founded in policy, market organisation and product design. It is analysed with regard to impacts on expected value, risks, and on the distribution of responsibilities. Table 1 provides an overview of these distinctions.

Due to the developments described above, the value of flexible demand can be expected to increase and structural barriers should decline. To improve incentives on the demand side, the primary policy focus should be directed to the design-related barriers. With regard to regulatory intervention it is important to acknowledge that the design of incentives and the resulting informational flows contribute to the missing activation of demand-side flexibility potential. By looking into market rules and product definitions it can be shown for the Danish case how market design aspects and barriers relate.

The following sections at first evaluate design-based risks related to demand-side participation in existing flexibility markets. Subsequently, the design issue of imperfect information about the underlying value of flexibility is discussed. A third section deals with the distribution of 
Table 2: Design-based barriers in flexibility products

\begin{tabular}{lll}
\hline & Market design & Design-based barriers \\
\hline Forwards & - Continuous trading & - Timing structure does not reflect flexi- \\
& - Peak/base contracts & bility supply/demand \\
& - Price differences provide incentive for load shift & - Minimum bid size of 1 MW \\
& - Value locked-in immediately & \\
& - Quantity risk due to uncertainty about volumes and & \\
Day-ahead & - load pattern & \\
& - Paily auction with hourly resolution & Trading lead times do not fit planning \\
& - Close to actual value based on marginal costs & - Minimum bid size of 0.1 MW \\
& - Risk/opportunities from price spikes & \\
Intraday & - Risk due to unplanned imbalances & \\
& - Continuous trading with hourly resolution & - No auction to determine clearing price \\
& - Adjustment market with limited liquidity & and gather liquidity \\
Real time & - Reflects (firm) expectations about the state of the & - Automation may be required \\
& physical system close to delivery & - Minimum bid size of 1 MW \\
& - Physical deviations create demand for regulation & - Short activation lead time requires au- \\
& - Available capacities submit hourly bids & tomation \\
& - Intra-hourly activation & - Penalties for non-availability \\
& - Reflects immediate system costs of flexibility & - Minimum bid size of 10 MW \\
& - Substantial price risk/opportunities & \\
\hline
\end{tabular}

market responsibilities and how the established market organisation may impede development of demand-side flexibility. All sections conclude with policy measures to address the identified barriers.

\section{Risks related to product design}

The underlying flexibility incentive of electricity market products relates to the supply and demand balance of flexible capacity within the respective time frames of the products. This is reflected in price differences encouraging a load shift, or price spikes (both upwards and downwards) encouraging a change in instantaneous consumption. An exception is a capacity market, like the one for reserves, that remunerates the potential for adjustments in production or consumption.

As the exact supply and demand situation for flexibility is uncertain the exact value of flexible capacity cannot be known in advance. This is a basic market risk that also will be reflected in the prices of the products; but as such it is not caused by the design of the products. In this section only design-related risks shall be discussed.

Table 2 sums up the characteristics of different flexibility products traded publicly in the Nordic system. It shows basic market design aspects as well as the related barriers to demand-side flexibility due to product design. Many of the barriers can be associated with an increased risk in relation to the value of flexibility. 


\subsection{Trading lead times}

The demand side is usually forecast on a day-ahead basis, sometimes merely based on fixed standard profiles. While providing active and reliable response requires precise forecasts, these also become more challenging to generate. Long lead times in traded markets will result in a higher risk of deviating from a promised response, although smart metering certainly would make better forecasting possible over a shorter time horizon.

As of now, traded markets require lead times and determine prices based on bids from market participants. Ideally, the demand side would respond to prices reflecting real-time system conditions. Although the system operator publishes real-time balancing prices, under the current market rules they do not provide an incentive to utilise short-term flexibility. By definition, to encourage bidding into existing markets, passive regulation (without submitting regulation bids) cannot surpass spot market value. All relevant flexibility products are traded with specified lead times.

Daily unit commitment has been organised around big and centralised production units. The lead time required for their dispatch is very different from that of small-scale demand-side activities. Nevertheless, the hourly day-ahead price for most actors determines volumes planned to produce and to consume, respectively.

In the Nordic system, the day-ahead market forms the benchmark for the settlement of forward financial contracts (NASDAQ OMX, 2013). Also the day-ahead prices are used as a baseline for the real-time market (Energinet.dk, 2008). These design features make it a central market place for the trade of flexibility.

It has therefore been a prominent market place for the pass through of price signals to the demand side (e.g., Hirst, 2002). Day-ahead prices come close to the actual value of electricity in a specific hour and at times provide substantial incentives for demand response due to spikes or even negative prices in some hours.

Most demand-side actors, however, will not be able to schedule their response actions in advance with the necessary lead times. They will therefore not be able to recover the full day-ahead value. If their characteristics require shorter lead times, flexibility could instead be offered closer to real time on the intraday or regulating markets.

The intraday market is a short-term hourly market mainly used to react to new information and unforeseen events. Some design features of the intraday market make direct utilisation of the demand side a bit more challenging. It is based on continuous trading; the delivery for a particular hour may be traded at several different, potentially quite volatile, prices only valid for the two involved parties. Thus, it may be the case that the individual price and a resulting reaction are not based on the average value of flexibility.

The real-time or regulating market is organised by the transmission-system operator to ensure that no physical deviations occur. Available flexibility may bid into the regulating market while the flexibility demand arises from physical deviations from scheduled transactions resulting in an obligation to trade at the real-time system price. This market reflects the immediate system costs of flexibility and thus provides substantial value potential.

Activation of real-time resources happens in a cascade of automatic reaction of units within seconds and manual regulation within the time frame of minutes. The bidding lead time for 
regulation is 45 minutes. The activation lead time, however, will be a maximum of 15 minutes only. In most cases, additional investments in automation equipment are required if decentralised resources are to participate at all.

\subsection{Penalties}

Harsh penalties may be prohibitive to small and new market participants. In the traditional markets participants commit firm volumes. The day-ahead market conveniently determines prices before actual delivery, allowing them to be easily communicated to all relevant parties. But they will be the result of an auction requiring commitment of firm volumes. Deviations from committed volumes will usually have a value that is different from the discovered prices.

Closer to delivery, market prices approach the actual value of electricity at a particular point in time. Market trading still occurs after the day-ahead market has closed. This means that deviations incur costs, while the providers of flexibility generate additional income for providing the service.

Availability of committed capacity therefore is subject to risk. The risk may be increased by market design features, for example the above mentioned lead times. The cost should be determined by the basic market structure and reflect system costs to replace the capacity at short notice. This cost, however, may be further increased by the design of penalties forming an additional barrier for small market participants. Penalties can be included in balancing prices and in the rules for regulating power.

The risk of imbalances can hardly be avoided. The market-design aspect lies in the definition of balancing rules and price mechanisms. A penalty in imbalance prices can have the form of a simple premium. But it may also be the result of an inefficient regulating power market resulting in higher costs for balancing.

The regulating market, typically backed up by reserve markets, organises the forward trading of reliability provision. Flexible capacities may participate in these markets and receive payments for availability. The system operator commits these capacities to remain available for regulation within a specific time frame.

A risk for providers of flexibility lies in potential penalties from not providing the announced regulation. A particularly harsh penalty is the threat of disqualification from further market participation.

Clearly, the system operator requires reliable forecasts and resources to balance the system. However, even if aggregated in larger portfolios, decentralised resources will have difficulty marketing their flexibility through the traditional products if the risks of imbalances and penalties in the regulating markets are too high.

\subsection{Hedging instruments}

The participation of demand-side flexibility in electricity markets will most likely require upfront investments in additional communication infrastructure, automation equipment, and in-house displays (e.g., Strbac, 2008). As the long-term revenue from such investments will be uncertain to some extent, market participants may want to be able to hedge some of the involved risks. 
At present, forwards are the only long-term contracts that may be used to lock-in the value of a load-shift potential, thus forming a basis for investments in necessary equipment. In the forward market, buyers and sellers commit to certain quantities before actual delivery, for example for the upcoming month over several years. Usually contracts are traded as peak or base load deliveries. Price differences between the two will provide incentives for flexible capacities to shift production or consumption from one period to the other.

Forward contracts for electricity deliveries are the basis for pricing most traditional end-customer contracts (see also Burger et al., 2007, p. 220ff.). Therefore expected price differences between peak and off-peak periods are passed through to the demand side. Accordingly, a customer who is able to influence his load shape may be able to achieve favourable prices in contracts based on the forward market.

A design issue with forwards is that as they represent expected averages over longer periods, incentive effects will be dampened. This is partially due to the fact that future load is unknown and it may not make sense to trade in more precise volumes, such as hourly profiles.

Large shares of demand-side flexibility potential do not fit with the design of forwards, limiting their usefulness as an instrument to hedge such activities. To support investments in responsive technologies different products or tariffs will be required.

\subsection{Policy measures: Consideration of risks}

Providing flexibility is a completely new function for most of the demand side. It may be a valuable service for the system but its value is very volatile and to a large extent uncertain. Precise timing and forecasting is crucial.

The availability of flexible demand-side resources is more uncertain than that of centralised units. In a system with large shares of intermittent production, the demand for flexibility also is uncertain. It may therefore become increasingly necessary to commit capacities closer to delivery and more frequent than is the case today. At the moment this need is met via intraday trading platforms. However, auctions may be a more suitable way to market small capacities. They would make pricing more transparent while also gathering the existing liquidity in the market and lowering the risk of failing to find a counterparty for an intraday trade. Having several auctions a day would be an option.

The Nordic regulating power market already provides a market place for short-term flexibility. The rules can be regarded as rather accommodating and generally suited for participation by decentralised actors. In particular, short lead times in the bidding process allow for small participants to gain a sufficient amount of information before submitting bids.

Still, the submission of bids and commitment of capacities may prove to be difficult with demandside resources. For that reason, the concepts of bidless real-time markets (as proposed by Ding et al., 2012) would make it possible to provide prices ahead of the actual delivery and communicate respective signals (volume or price) to customers.

The risk of penalties in the Danish case is limited at present. A deviation from the schedule may, however, have a significant effect. Costs are incurred through the balancing mechanism. Its design should therefore consider whether a risk imposed through balancing costs is appropriate and not 
prohibitive for active demand-side participation. This to a large extent depends on competitive regulating markets that do not exclude any capacities from participating.

If investments are a prerequisite to participate in flexibility markets, uncertainty related to the long-term value of flexibility may become an issue. As described above, existing forward products seem to provide only limited help in this regard. As the forward market is organised by commercial actors, it is unlikely that new products will emerge in the short run. Complementary policies and pricing schemes that help demand-side actors to plan for longer time frames could be a temporary solution (see also Alexander, 2010).

A good example of investments based on long-term price incentives is the installation of large thermal stores at Danish decentralised combined-heat-and-power plants. They have mostly been based on a three-level tariff, which is only slightly more variable than the two levels of Nordic forward markets (cp. Togeby et al., 2009). Similar tariff schemes backed by legislation could be imagined for demand response as well.

\section{Barriers to discovering the value of flexibility}

Information about supply and demand for flexibility contained in the prices of existing products (Table 2) is limited to the scope of the products. Any demand or potential supply that does not fit with the predefined timing or location will not be allowed to participate. Besides indicating a possibly low value of flexibility due to the basic market structure, the imperfect information may be one of the reasons why incentives from traded products are often found to be too weak to establish demand response (see Chao, 2010, Singh and Østergaard, 2010, Strbac, 2008).

The discussion in this section suggests that existing products and markets do not reveal the full value of flexibility. The decentralised part of the demand for flexibility is hidden. If flexibility remuneration mechanisms can be designed to reflect needs at higher resolutions in time and location, then it will become more attractive to activate decentralised resources.

\subsection{Locational information}

At some level of penetration with variable renewable production connected to regional and local grids, signs indicate a demand by the system that cannot be suitably addressed with existing products. If not coordinated, the use of some products at system level may even increase localised demands.

Local regulation and re-dispatch is already taking place on a bilateral basis to ensure power-system stability. The extent of such flexibility actions without public price signals may become significant with increasing shares of distributed production. One example is the extensive regulation of wind power in North-Eastern Germany (cp. Bömer, 2011). In 2012, the amount paid to regulate German renewable energy plants in this way was almost half of the amount spent on the comparable service of tertiary reserves the same year (cp. Bundesnetzagentur, 2013).

In the future, regulation in the opposite direction may become a growing issue. Such sub-market regulation is not reflected in current prices, raising questions about the possibility of including a larger share of the actual value of decentralised flexibility resources in existing or new market products. 
According to the expectations about future challenges in distribution grids, it is likely that some value is hidden from the current markets at the regional and local levels. Challenges for distribution-system operators will originate from increased installation of distributed generation and potentially from new electrical loads associated with electric vehicles and heat pumps.

If regulation services must be provided at lower voltage levels, demand-side resources would be very well suited to provide those (cp. e.g., Csetvei et al., 2011, Shaw et al., 2009). This will eventually help reduce the need for capacity investments (Dansk Energi and Energinet.dk, 2012). Value created in this way should be reflected back onto the actors creating it, which may allow some demand-side resources to become competitive with conventional measures (CIRED, 2013).

\subsection{Timing prerequisites}

Market-design barriers regarding the time frame for providing existing products are closely related to the characteristics and technical capabilities at the demand side. Decentralised flexibility resources will differ in the services they are able to provide (cp. Hirst and Kirby, 2001). Some may have limits regarding the duration of their response; others may not be able to return to previous load levels fast enough. Such resources have limited value within the current framework, although they could be well suited for new or slightly adjusted services.

In the Nordic system, both the day-ahead and the intraday markets are settled on an hourly basis. Any provider of flexibility on these markets, therefore, must be able to react for at least one hour. If load shifting is involved, both the increase and the decrease of load is required to have a duration of at least one hour. For many residential appliances this will be prohibitive unless they are pooled and controlled in an aggregated way to fulfil the market requirements.

The timing requirements of products on the regulating power market may be a challenge as well. Although Denmark provides rather flexible conditions in support of decentralised production units, integrating the demand side into this market remains a big step.

\subsection{Policy measures: Product definitions to reveal full value}

A market for flexibility services on a more local level is being widely discussed. On the one hand, such markets could help to solve regulation tasks at the distribution level. On the other hand, they may become necessary as a coordinating mechanism if increasingly transmission-system services are supplied by demand-side resources, thus putting more pressure on distribution grids (cp. Medina et al., 2010).

It is still somewhat open what kind of products should be traded on such markets (proposals for the Danish case can be found in Energinet.dk and Dansk Energi, 2012, Ding et al., 2013). One of the challenges is to design them in a way that does not conflict with the existing set-up at system level. Continuous coordination mechanisms between system and local levels will most likely be required (Friedrichsen, 2012).

In general, the demand for flexibility at the distribution-grid level is not easily addressed through market-based arrangements. At low-voltage levels, the need very much depends on the layout of the local grid infrastructure (DENA, 2012). Therefore, tendering standardised products may sometimes be difficult, as demand can be very specific. The grid operator should avoid paying for 
resources not actually required. Yet knowing when to upgrade the grid and socialise costs among all users instead of applying local incentives is also a critical policy issue (cp. Csetvei et al., 2011).

From a timing perspective conclusions on changes in market design seem less clear than from a locational perspective. To achieve full efficiency prices should reflect real-time conditions of the power system. However, it is not certain that such volatile price information would lead to the most efficient response from the demand side. Frequent price changes to prompt changes in consumption behaviour may result in consumers getting tired of reacting and, eventually, becoming less responsive (Kim and Shcherbakova, 2011). Of course, for automated load control this will not be an issue. Automated and manual demand response should therefore be targeted at different time scales.

\section{Barriers in the design of roles and responsibility}

Defining clear incentives and adequate risks towards the demand side is an important foundation for activating flexibility potential. Moreover, the incentive structures in the market also require a suitable division of roles and responsibilities. Adoption of demand response contracts and flexible technologies only makes sense in a model that can communicate the right information and make use of the responsive behaviour of small units.

Market-structural factors, such as costs and risks of participating in flexibility markets, naturally lead to an aggregation of capacities and centralisation of responsibility for such portfolios. However, various design elements contribute to predefining roles and responsibilities as well and these may impede the development of an active demand side.

Product definitions are important in this respect too as they implicitly or explicitly contain pooling requirements for participating capacities. But delegation may also be built into policies and market regulations, leaving no choice to actively take responsibility.

Here the focus will be on information flows within the Danish model. Essential information on the demand for flexibility is contained in short-term price signals. Initially, the market-role model determines who receives such signals, defining the type of actors allowed in the market and how communication must take place amongst them.

On the other hand, communicating demand-side activities back to the market without significant delay is just as important. Besides the definition of market roles, balancing and settlement rules for demand-side volumes are important in predefining how potential flexibility is aggregated and whether it can be utilised in the market places.

\subsection{Pooling requirements}

To some extent, some of the market-design issues mentioned in Sections 3 and 4 are currently mitigated by the pooling of smaller capacities. If one unit cannot fulfil the requirements, then perhaps another portfolio of units will do so.

Minimum bid-sizes in the markets represent an explicit pooling requirement if small capacities are to participate. While the Nordic spot market enables trading of relatively small lots of $100 \mathrm{~kW}$, 
long-term forward and intraday trades have to cover at least $1 \mathrm{MW}$. The regulating power market has a minimum bid-size of $10 \mathrm{MW}$.

Besides the mere volume requirements, timing also plays a role. The day-ahead and intraday markets cover settlement periods of one hour. Forward products cover far longer periods. The underlying physical capacities must match these time patterns as deviations will have to be settled in the balancing market at an additional cost. Portfolio aggregation is the only practical solution.

The attractive market for regulating power features a few more implicit pooling requirements besides the explicit minimum bid size. While committed capacity will have to stay available for at least one full hour, activation is scheduled only in 5-minute intervals. At the same time, complying with a potential activation of one whole hour or only five minutes may be very difficult without aggregation of many small units. Moreover, to mitigate the risk of a unit not being available for regulation it may become necessary to hold reserve capacity within the portfolio, depending on what level of penalties to expect.

The result is that the only practical access to flexibility markets is through centralised aggregation. Direct market participants will have to translate market products into products for the demand side. Pooling then can become complex and, inevitably, pooling providers will add risk premiums to cover any differences in value between wholesale and demand-side products.

This creates additional design-related costs for demand-side flexibility. Moreover the pooling of smaller capacities limits taking into account individual preferences. Unless it is possible to pool units with like preferences, this would reduce the efficiency of demand-side flexibility.

\subsection{Information flows in the market-role model}

All incentives must work along given lines of communication, determined to a great extent by the model of market-roles. In liberalised markets, the model assigns responsibilities to different actors and defines indispensable information flows. In this way, the market-role model enables efficient handling of the processes required to run functioning wholesale and retail markets while continuously maintaining system reliability.

The following observations are organised around the current Danish model of market roles (Energinet.dk, 2007). As the Danish model reflects the harmonised European electricity marketrole model (ENTSO-E, 2011) the observations to some extent apply for other European markets as well.

The model of roles as shown in Figure 1 describes informational flows between different actors related to price and quantities on a short-term basis (at least daily exchange of information). These flows are most relevant to the provision of flexibility.

The grid and system operators as well as grid-connected parties, both consumers and producers, make up the physical side of the system. The commercial actors are shown on the right side and consist of suppliers and balancing responsible parties [BRP].

Grid and system operators may set the terms and incentives to ensure reliability in the physical system entering into contractual relations with the commercial actors. Consumers as well as generating plants are obliged to enter agreements with a supplier that assumes the obligation to supply certain loads and to off-take produced electricity. The supplier then has to make sure that all production and consumption is part of a BRP's account. 


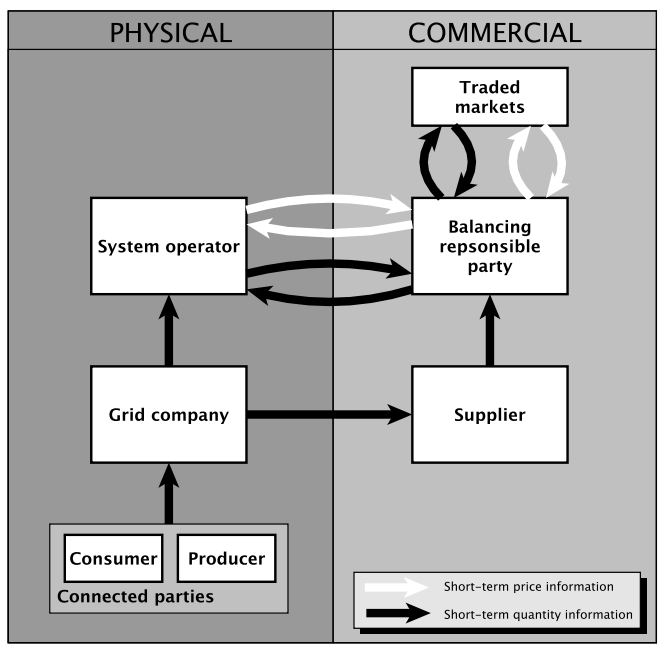

Figure 1: Market-roles and short-term informational links in the present model

Such contractual links often include some form of information exchange regarding volume and price. Those long-term links are omitted in Figure 1 as they only contain limited information on the actual value of flexibility. Some degree of information may be transferred by implementing time-of-use pricing within a contract; the flexibility incentive, however, will be weaker.

Due to explicit and implicit pooling requirements, aggregation takes place on the commercial side as to make portfolios fit with wholesale products and system services. The only commercial party receiving initial short-term price information is the BRP. It is thus the only role that is obliged and incentivised towards the system operator to maintain a balanced portfolio in the short-term. This way, it has become the central role on the commercial side to communicate demand for reliability in the system by trading with other BRPs and by distributing control signals to connected parties possibly through their respective suppliers.

In principle the preconditions to market flexibility from demand-side actors are given, also under the present conditions and by the use of existing products. Most of the activities related to bringing new demand-side flexibility to the market would have to be organised around the role of the BRP. Either existing BRPs in the market would take that role, or alternatively other actors would have to assume the role of a BRP.

As the market model in its present form does not distribute price information to the demand side, this would have to be done by commercial actors as well. In that case, to establish the required informational links between demand side and flexibility markets, suitable commercial agreements would have to be negotiated (see also He et al., 2013).

In Figure 2 communication between the BRP and connected parties is indicated by an additional price link. Signals to the demand side may instead contain quantity information or quantityrelated information, such as temperature set-points (see also Ikäheimo et al., 2010, for examples of different signals).

New informational flows would also have to be established if flexibility products are to address a 


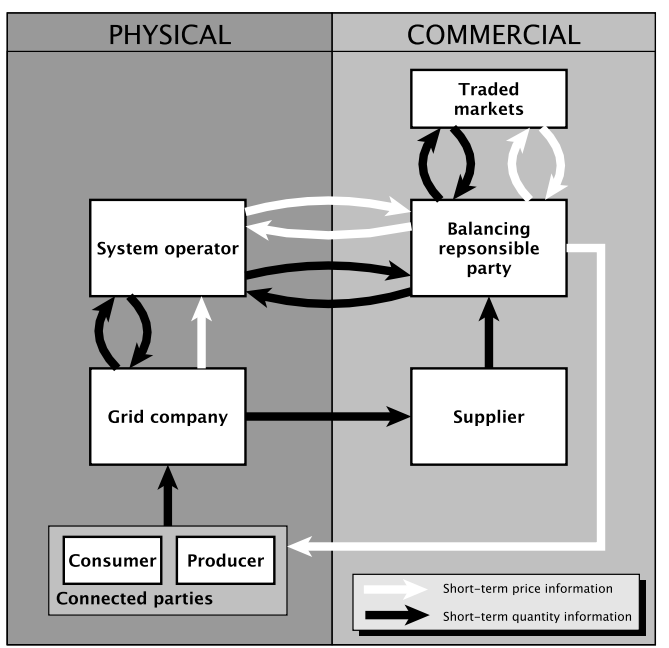

Figure 2: Market-roles including DSO price information links

local demand. Figure 2 also provides an example of how the informational flow from local grid companies could be extended to include signals about flexibility and its potential value. In this first, step it is not important to whom these signals are sent as long as they are received by one of the commercial actors at some point.

\subsection{Aggregation and settlement of demand-side volumes}

At this point in time, it is still somewhat unclear which market role should be expected to initiate the development of decentralised flexibility resources. Internationally, countries are following diverse approaches (cp. Brandstätt et al., 2012).

Denmark is pursuing a market-based approach that puts responsibility for developing suitable products with the commercial actors to the greatest extent possible. Although some degree of direct regulation by grid operators may still be necessary (cp. Energinet.dk and Dansk Energi, 2012), this might conflict with the evolving retail market model (Danish Energy Agency, 2012). This new model is aimed at establishing the supplier as the single point-of-contact for end customers. This commercial role would clearly have to be included in the facilitation and operation of demand-side flexibility.

The challenges of pooling in order to participate in the market were described above. In addition, pooling only makes sense if balancing and settlement rules for the demand side are consistent with the requirements of market products.

As indicated by the black arrows from the connected parties and further upwards in Figures 1 and 2 , short-term changes in demand-side volumes must be reflected back to the commercial side and onto the respective wholesale balancing accounts. At present, in Denmark as in many other markets, this only happens for large customers (annual consumption of at least $100 \mathrm{MWh}$ ).

Unless they accept a significant increase in their metering tariff, smaller customers will be settled based on the same hourly profiles valid for all customers in the distribution grid area. Even if 
hourly metering is installed, the actual consumption will not have an immediate effect on the market portfolio of the balancing responsible party. Thus, it will not be possible to earn a profit from potential response actions, which presents a severe design-related barrier to demand-side flexibility.

\subsection{Policy measures: Ensure adequate aggregation}

Enforced centralisation should be viewed as an important policy issue regarding the aggregation of demand-side flexibility. Aggregation should be an active choice based on fundamental economics and not a requirement in market regulations.

In the case of product definitions in the regulating power market the issue of bid sizes and demand-side participation is already being discussed by regulatory policy-makers (Bang et al., 2012). A change in the timing of products, however, does not seem to be on the way. The neighbouring German market, by comparison, has 15-minute settlement periods and is preparing to introduce 15-minute day-ahead contracts. For some decentralised resources this could be an attractive option.

Substantial changes to the model of market roles are unlikely in the near future, and activation of flexible resources has to primarily rely on commercial initiatives within the defined framework of roles. As long as reliability is maintained, it makes sense from the perspective of the system operator to keep this set-up. Adjustments could still be achieved by introducing new flexibility products.

Concepts of flexibility products at distribution-grid level are being developed. A model in which the system operator then would coordinate both local and system-wide flexibility demand and exchange information with the BRPs has been proposed by the Danish system operator (cp. Energinet.dk and Dansk Energi, 2012). Alternatively, grid companies could also enter into agreements with the commercial side directly.

At present, on the commercial side, BRPs are the central hub for flexibility information, while at the same time their connection to the demand side is still rather weak. This unbalanced constellation could impede the creation of a more active demand side.

The adoption of demand flexibility by commercial actors could be supported by establishing a more direct link to the relevant markets. With BRP aggregation there will be a chain of communication and contractual links between consumer and markets. While it may be possible to break up this chain or shorten some of the links by integration of roles or by commercial agreements within the present model, another option is to create a link by re-designing the market communication model.

This could imply introducing new roles or requiring different communication flows. With regard to local flexibility products, defining new responsibilities for demand-side aggregation might be considered, such that the provision of flexibility may be handled separately.

The introduction of a new aggregator role is frequently brought up in discussions about demand response, but it may be interpreted very differently (e.g., Ding et al., 2013, Energinet.dk and Dansk Energi, 2012, Ikäheimo et al., 2010). In principle, the role contains elements of both suppliers and BRPs in that it involves gathering a portfolio of customers like a supplier, while at the same time, at least to some extent, it includes responsibility for marketing flexibility (similar to a BRP). 


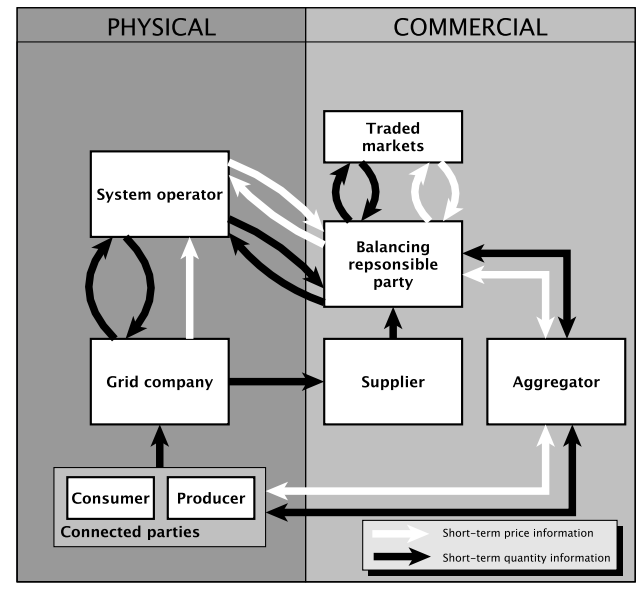

Figure 3: Market-role model including aggregator

How to treat this role within the market-role model is unresolved as it is somewhat unclear where it would fit into the picture. Some argue that although it would be necessary to establish such actors, they would still have to refer to a BRP that takes final responsibility for marketing and balancing of flexible capacities (as in Figure 3). The Danish system operator favours such a set-up (cp. Energinet.dk and Dansk Energi, 2012). It does not necessarily add anything new, as it would essentially still be a BRP aggregation model.

It would mean a substantial change, however, if the new role represented self-contained flexibility aggregators. Such actors would have to be able to market flexibility independent of the supply of electricity. One aggregator presumably would have to refer to several BRPs, which would be somewhat contradictory to their aggregation role. It might be more obvious to let such aggregators refer to the system or grid operators directly to market their flexibility in a truly aggregated manner (see Figure 4).

Some see such an aggregator role as new pivotal point for the marketing of flexibility services separate from existing roles (cp. Ding et al., 2013). However, as this model for some parts separates flexibility from the energy delivery, a flexible customer would have to be affiliated with both a supplier and an aggregator. While the supplier would have to procure energy for the customer, the aggregator would need to manage the flexibility.

The advantage of a set-up with separate flexibility aggregation would be that it creates an open market with competition among aggregators over flexibility capabilities of the demand side. It would however, require substantial adjustments to settlement rules in order to not affect the balancing responsible of the energy deliveries. It may also open up the possibility of managing different appliances behind the same meter by different aggregators. For household customers, in particular, this may create more transaction costs than actual benefit.

While separating flexibility marketing may be a workable idea, the most practical model to implement it is probably to integrate the flexibility aggregation role with the supply task. In this model, retailers would also be able to aggregate and market the flexibility of their customers 


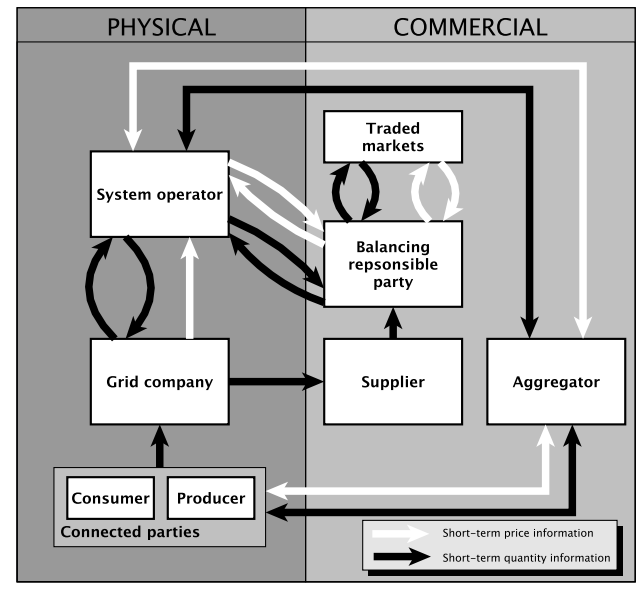

Figure 4: Market-role model including aggregator with direct market access

(Ikäheimo et al., 2010). This would ensure that although flexibility could be marketed directly (with for instance the grid company) all adjustments would happen within the same balancing account and settled volumes at the BRP level could be more easily corrected for flexibility actions.

Under a supplier aggregation model the coordination requirements for the system operator and potentially also the BRP will inevitably increase. The model may be attractive to the suppliers and in particular to the customers maintaining a single point-of-contact to the electricity market (cp. Scheer and Strömbäck, 2010). As acceptance and adoption is one of the major issues for demand-side flexibility, this may prove to be valuable.

Table 3 provides an overview of consequences to the different market roles of the discussed approaches for allocating the demand-side flexibility aggregation task. Aggregation by BRP, supplier, or a new aggregator role is compared to the current status. Coordination requirements increase as soon as flexibility aggregation happens around the BRP. At the same time the opportunities for the provision of demand-side participation and new services will improve.

In any case it would first be necessary to establish adequate settlement rules. Real-time metering and frequent settlement is costly and not yet feasible for small consumers. The usual tariff for hourly metering with daily settlement lies at almost 700 EUR per year and will only be borne by larger customers.

For now, only proposals for intermediate solutions exist that aim at a compromise between efficient informational flows and cost by introducing hourly metering with monthly settlement (Danish Energy Regulatory Authority, 2012). This way the flexibility potential can only be utilised to a limited extent, as response actions would not have direct influence on the market portfolios. To communicate price signals towards the demand side, however, this is a good starting point that should be further developed. 
Table 3: Implications of different aggregation models on market roles

\begin{tabular}{|c|c|c|c|}
\hline Market roles & Continued BRP aggregation & Supplier aggregation & Separate aggregation role \\
\hline System operator & $\begin{array}{l}\text { - Additional coordination } \\
\text { with distribution level }\end{array}$ & \multicolumn{2}{|c|}{$\longleftrightarrow \begin{array}{l}\text { Potentially increasing coordination } \longrightarrow \\
\text { with new counterparties }\end{array}$} \\
\hline Grid company & $\longleftarrow$ & \multicolumn{2}{|l|}{$\begin{array}{l}\text { Potential access to new ser- } \\
\text { vices }\end{array}$} \\
\hline BRP & $\begin{array}{l}\text { - Dependence on cooperation } \\
\text { with suppliers } \\
\text { - Potentially increasing com- } \\
\text { petition from new BRPs }\end{array}$ & \multicolumn{2}{|c|}{$\begin{array}{l}\longleftarrow \\
\text { Potential for cooperation } \\
\text { Potentially increased coordination }\end{array}$} \\
\hline Supplier & $\begin{array}{l}\text { - Dependence on cooperation } \\
\text { with BRP }\end{array}$ & $\begin{array}{l}\text { - New business opportunities } \\
\text { - New competencies required }\end{array}$ & $\begin{array}{l}\text { - Potentially increased coor- } \\
\text { dination } \\
\text { - Increasing competition }\end{array}$ \\
\hline Demand side & $\begin{array}{l}\text { - New options offered by (po- } \\
\text { tentially unknown) special- } \\
\text { ists }\end{array}$ & $\begin{array}{l}\text { - Comfortable access } \\
\text { through single-point-of- } \\
\text { contact }\end{array}$ & $\begin{aligned} \text { - New options offered by (un- } \\
\text { known) specialists } \\
\text { - Potentially several new con- } \\
\text { tractual counterparties }\end{aligned}$ \\
\hline Aggregator & $\begin{array}{l}\text { - Dependence on cooperation } \\
\text { with BRP }\end{array}$ & $\begin{array}{l}\text { - Dependence on cooperation } \\
\text { with suppliers }\end{array}$ & - New business opportunities \\
\hline
\end{tabular}

\section{Conclusion}

As Section 2 suggests, flexible capacities on the demand side may become valuable to the electricity system if enabled to take over reliability tasks. The level of adoption of this new function is critical for a policy strategy aiming at utilising demand-side flexibility potential.

Establishing informational links is a fundamental precondition for having the demand side actively participate in the market. While the smart meter roll-out is firmly seated on the political agenda, it is questionable whether the relevant actors can be forced to implement dynamic pricing or other incentive-based schemes and whether consumers can be motivated to adopt such schemes.

From a policy perspective, it will be important to establish economically efficient solutions that also work in an international context, especially within the common European electricity market. Emphasis has to be placed on the right issues. As Section 2.4 points out, some barriers have their background in the fundamental characteristics of the electricity market structure such that intervention may create inadvertent inefficiencies.

The policy priority should thus be on addressing barriers in market rules, products, and existing regulation. This analysis identifies the design of incentives, their expected value and related risks as well as the distribution of roles and responsibilities, as key elements for successful activation of demand-side flexibility.

Important design-related barriers due to the implicit risks of applying existing market products to flexible demand were examined in Section 3. They include short trading lead times, penalties and inappropriate hedging instruments. Regulatory options to consider include short gate-closure times and more frequent auctions. Moreover, pricing schemes with a high degree of certainty about price levels could improve investment incentives.

Imperfect information about the timing and location of physical demand for flexibility were described in Section 4. A first step towards improving imperfect information about locational 
flexibility needs would be to implement coordinating mechanisms between the system operator and local grid operators regarding the demand and availability of flexibility. This would also be a precondition for efficiently utilising demand-side resources for system services. Such mechanisms may eventually develop into market platforms at the distribution-grid level. Information about timing may be improved by refining the rules of regulating power markets and possibly by shorter settlement periods.

Section 5 looked into the delegation of responsibility from many decentralised actors to a few wholesale market participants as well as the route of information between markets and the demand side. An important precondition is to establish a settlement system that reflects response actions back onto market portfolios.

Regarding aggregation, the model of continued BRP aggregation has some clear advantages. It would keep flows simple and utilise established processes. However, it is dependent on cooperation between BRPs and suppliers and may favour incumbent market participants.

Separating responsibility for demand-side flexibility from the usual BRP tasks would indeed be another option, but it would require extending the current model with a new aggregator role. To avoid the risk of designing new barriers and additional transaction costs, it seems recommendable, to initially let existing roles (that is, suppliers) handle the aggregation task for demand flexibility, with only minor adjustments to the current market-role set-up.

A big challenge following the roll-out of smart metering lies in activating the potential for demand response by inducing the adoption of smart technologies and matching electricity market products. Future research should consider incentives and barriers faced by different kinds of demand-side actors, including the potential transaction costs. The expected increase in the demand for flexibility will be the major driver for new capacities. Market-design barriers should stay in the focus of researchers and policy-makers to not impede the development of beneficial flexibility.

\section{Acknowledgement}

The work has greatly benefited from various discussions with Stine Grenaa Jensen, Energinet.dk as well as Poul-Erik Morthorst, DTU. Moreover, the author gratefully acknowledges the funding as part of the INCAP project by the Danish Council for Strategic Research.

\section{References}

Albadi, M. H., El-Saadany, E., 2008. A summary of demand response in electricity markets. Electric Power Systems Research 78 (11), 1989-1996.

Alexander, B. R., 2010. Dynamic pricing? Not so fast! A residential consumer perspective. The Electricity Journal 23 (6), 39-49.

Andersen, F. M., Jensen, S. G., Larsen, H. V., Meibom, P., Ravn, H., Skytte, K., Togeby, M., 2006. Analyses of demand response in Denmark. Ris $\varnothing-\mathrm{R}$ Report 1565, Ris $\varnothing$ National Laboratory, Roskilde, Denmark.

Bang, C., Fock, F., Togeby, M., 2012. The existing Nordic regulating power market. FlexPower WP1 - Report 1 , Copenhagen.

BMU, 2012. Bericht der AG 3 Interaktion an den Steuerungskreis der Plattform Erneuerbare Energien, die Bundeskanzlerin und die Ministerpräsidentinnen und Ministerpräsidenten der Länder. Plattform Erneuerbare Energien, Bundesministerium für Umwelt Naturschutz und Reaktorsicherheit, Berlin.

URL http: //www.bmu.de/fileadmin/Daten_BMU/Bilder_Unterseiten/Themen/Klima_Energie/

Erneuerbare_Energien/Plattform_Erneuerbare_Energien/121015_Bericht_AG_3-bf .pdf 
Bömer, J., 2011. Abschätzung der Bedeutung des Einspeisemanagements nach EEG 2009: Auswirkungen auf die Windenergieerzeugung in den Jahren 2009 und 2010. Prepared for Bundesverband Windenergie, Ecofys, Berlin. URL http://www.wind-energie.de/sites/default/files/download/publication/ abschaetzung-der-bedeutung-des-einspeisemanagements-nach-eeg-2009/2011-10_ecofys_ einsman.pdf

Brandstätt, C., Friedrichsen, N., Meyer, R., Palovic, M., 2012. Roles and responsibilities in smart grids: A country comparison. In: 9th International Conference on the European Energy Market 2012. IEEE.

Bundesnetzagentur, 2013. Monitoringbericht 2013. Report pursuant to the German Energy Industry Act (EnWG) and Act Against Restraints of Competition (GWB), Bundesnetzagentur, Bonn.

URL http: //www . bundesnetzagentur.de/SharedDocs/Downloads/DE/Allgeme ines/ Bundesnetzagentur/Publikationen/Berichte/2013/131217_Monitoringbericht2013.pdf

Burger, M., Graeber, B., Schindlmayr, G., 2007. Managing energy risk: An integrated view on power and other energy markets. Wiley.

Cappers, P., Mills, A., Goldman, C., Wiser, R., Eto, J. H., 2012. An assessment of the role mass market demand response could play in contributing to the management of variable generation integration issues. Energy Policy 48, 420-429.

Chao, H., 2010. Price-responsive demand management for a smart grid world. The Electricity Journal 23 (1), 7-20.

CIRED, 2013. Smart grids on the distribution level - hype or vision? cired's point of view. Working group on smart grids, final report, Congrès International des Réseaux Electriques de Distribution (CIRED).

Costello, K., 2004. An observation on real-time pricing: Why practice lags theory. The Electricity Journal 17 (1), $21-25$.

Csetvei, Z., Østergaard, J., Nyeng, P., 2011. Controlling price-responsive heat pumps for overload elimination in distribution systems. In: 2011 2nd IEEE PES International Conference and Exhibition on Innovative Smart Grid Technologies (ISGT Europe). pp. 1-8.

Danish Energy Agency, 2012. Notat: Engrosmodellen. Notat J.nr. 3401/1001-4031, Danish Energy Agency, Copenhagen.

Danish Energy Agency, 2013. Resumé af samfundsøkonomisk analyse ved fuld udrulning af fjernaflæste elmålere. Notat J.nr. 3401/1001-5643, Danish Energy Agency, Copenhagen.

Danish Energy Regulatory Authority, 2012. Analyse af konkurrencen på detailmarkedet. Report, Danish Energy Regulatory Authority, Valby, Denmark.

URL http://energitilsynet.dk/fileadmin/Filer/0_-_Nyt_site/EL/Nyheder/Analyse_af detailmarkedet_for_el.pdf

Dansk Energi, Energinet.dk, 2012. Smart grid i Danmark 2.0: Implementering af tre centrale anbefalinger fra Smart Grid Netværket. Tech. rep., Energinet.dk \& Dansk Energi.

Dansk Energi Analyse, Norenergi, 2005. Priselastisk elforbrug hos de større elforbrugere. Report prepared for Energinet.dk, Dansk Energi Analyse, Norenergi.

DENA, 2012. Ausbau- und Innovationsbedarf der Stromverteilnetze in Deutschland bis 2030: Endbericht. dena-Verteilnetzstudie, Deutsche Energie-Agentur, Berlin

Ding, Y., Hansen, L. H., Cajar, P. D., Brath, P., Bindner, H. W., Zhang, C., Nordentoft, N. C., 2013. Development of a DSO-market on flexibility services. iPower - WP 3.8, Strategic platform for innovation and research in intelligent power (iPower). URL http: //www . ipower-net.dk/\$\sim\$/media/iPower/Documents / iPowerWP38report80.ashx

Ding, Y., Nyeng, P., Østergaard, J., Trong, M. D., Pineda, S., Kok, K., Huitema, G. B., Grande, O. S., 2012. Ecogrid EU a large scale smart grids demonstration of real time market-based integration of numerous small DER and DR. In: IEEE Power and Energy Society Innovative Smart Grid Technologies Europe 2012. IEEE.

Droste-Franke, B., Paal, B. P., Rehtanz, C., Sauer, D. U., Schneider, J.-P., Schreurs, M., Ziesemer, T., 2012. Balancing renewable electricity: Energy Storage, Demand Side Management, and Network Extension from an Interdisciplinary Perspective. Vol. 40 of Ethics of Science and Technology Assessment. Springer, Berlin.

Earle, R., Faruqui, A., 2006. Toward a new paradigm for valuing demand response. The Electricity Journal 19 (4), $21-31$.

Energinet.dk, 2007. Regulation F: EDI communication, Appendix report 3: The Danish role model. Memorandum Doc. no. 141446-07, Energinet.dk, Fredericia, Denmark.

URL http: //WwW .energinet.dk/SiteCollectionDocuments/Engelskedokumenter/El/

RegulationFappendix3TheDanishrolemodel.pdf

Energinet.dk, 2008. Regulation C2: The balancing market and balance settlement. Doc no. 5452-09_v1, Energinet.dk, Fredericia, Denmark.

URL http: //energinet.dk/SiteCollectionDocuments/Engelskedokumenter/El/

RegulationC2Thebalancingmarketandbalancesettlement.pdf

Energinet.dk, 2013. Samfundsøkonomisk analyse af udrulning af fjernaflæste timeelmålere. Dok. 87409/12, sag 12/1549, Energinet.dk, Fredericia, Denmark.

Energinet.dk, Dansk Energi, 2012. DanGrid: Delrapport Arbejdsgruppe 22, endelig rapport efter høring 12. september 2012. Tech. rep., Energinet.dk, Fredericia, Denmark.

ENTSO-E, 2004. Operation Handbook. European network of transmission system operators for electricity, Brussels. 
ENTSO-E, 2011. The harmonised electricity market role model. ENTSO-E, EFET, ebIX, Brussels.

Faruqui, A., Harris, D., Hledik, R., 2010. Unlocking the $€ 53$ billion savings from smart meters in the EU: How increasing the adoption of dynamic tariffs could make or break the EU's smart grid investment. Energy Policy 38 (10), 6222-6231.

Faruqui, A., Sergici, S., 2010. Household response to dynamic pricing of electricity: a survey of 15 experiments. Journal of Regulatory Economics 38 (2), 193-225.

Faruqui, A., Sergici, S., Akaba, L., 2014. The impact of dynamic pricing on residential and small commercial and industrial usage: New experimental evidence from Connecticut. The Energy Journal 35 (1), 137-160.

Friedrichsen, N., 2012. Governing smart grids: the case for an independent system operator. European Journal of Law and Economics (Online First Articles).

URL http: //link. springer.com/10.1007/s10657-012-9345-0

Gül, T., Stenzel, T., 2005. Variability of wind power and other renewables: Management options and strategies. Tech. rep., International Energy Agency, Paris.

Greening, L. A., 2010. Demand response resources: Who is responsible for implementation in a deregulated market? Energy 35 (4), 1518-1525.

Grohnheit, P. E., Andersen, F. M., Larsen, H. V., 2011. Area price and demand response in a market with $25 \%$ wind power. Energy Policy 39 (12), 8051-8061.

He, X., Keyaerts, N., Azevedo, I., Meeus, L., Hancher, L., Glachant, J.-M., 2013. How to engage consumers in demand response: A contract perspective. Utilities Policy 27, 108-122.

Hirst, E., 2001. Price-responsive demand in wholesale markets: Why is so little happening? The Electricity Journal 14 (4), 25-37.

Hirst, E., 2002. Reliability benefits of price-responsive demand. IEEE Power Engineering Review 22 (11), 16-21.

Hirst, E., Kirby, B., 2001. Retail-load participation in competitive wholesale electricity markets. Tech. rep., Edison Electric Institute, Washington, D.C.

Ikäheimo, J., Evens, C., Kärkkäinen, S., 2010. DER Aggregator business: the Finnish case. VTT-R 06961-09, VTT Technical Research Centre of Finland, Espoo, Finland.

Kim, J.-H., Shcherbakova, A., 2011. Common failures of demand response. Energy 36 (2), 873-880.

Kirschen, D., 2003. Demand-side view of electricity markets. IEEE Transactions on Power Systems 18 (2), $520-527$.

Lund, H., Andersen, A. N., Østergaard, P. A., Mathiesen, B. V., Connolly, D., 2012. From electricity smart grids to smart energy systems - a market operation based approach and understanding. Energy 42 (1), 96-102.

Medina, J., Muller, N., Roytelman, I., 2010. Demand response and distribution grid operations: Opportunities and challenges. IEEE Transactions on Smart Grid 1 (2), 193-198.

Munksgaard, J., Morthorst, P. E., 2008. Wind power in the Danish liberalised power market-policy measures, price impact and investor incentives. Energy Policy 36 (10), 3940-3947.

NASDAQ OMX, 2013. Product specifications - Power. Accessed: 14-10-2013. URL http: //www . nasdaqomx.com/commodities/markets/products/power

Nicolosi, M., 2010. Wind power integration and power system flexibility-an empirical analysis of extreme events in Germany under the new negative price regime. Energy Policy 38 (11), 7257-7268.

Scheer, J., Strömbäck, J., 2010. Energy retailers' perspective on the deployment of smart grids in Europe. Tech. rep., European technology platform for the electricity networks of the future, Brussels.

Shaw, R., Attree, M., Jackson, T., Kay, M., 2009. The value of reducing distribution losses by domestic load-shifting: a network perspective. Energy Policy 37 (8), 3159-3167.

Singh, S., Østergaard, J., 2010. Use of demand response in electricity markets: An overview and key issues. In: 7th International Conference on the European Energy Market 2010. IEEE.

Slootweg, J. G. H., van der Meijden, M., Knigge, J. D., Veldman, E., 2011. Demystifying smart grids: Different concepts and the connection with smart metering. In: CIRED, 21st International Conference on Electricity Distribution.

Sorrell, S., 2004. Understanding barriers to energy efficiency. In: Sorrell, S., O’Malley, E., Schleich, J., Scott, S. (Eds.), The Economics Of Energy Efficiency: Barriers to Cost-Effective Investment. Edward Elgar, Cheltenham, UK, pp. 25-93.

Stoft, S., 2002. Power system economics: Designing markets for electricity. IEEE Press, Piscataway, NJ.

Strbac, G., 2008. Demand side management: Benefits and challenges. Energy Policy 36 (12), 4419-4426.

Togeby, M., Werling, J., Hethey, J., Bregnbæk, L., Kofoed-Wiuff, A., Lindboe, H. H., Mygind, K., Ahmt, J., Filippidis, A., Meibom, P., Morthorst, P. E., 2009. Bedre integration af vind: Analyse af elpatronloven, treledstariffen for mindre kraftvarmeanlæg, afgifter og andre væsentlige rammebetingelser. Report prepared for the Danish Energy Agency and the Danish Ministry of Taxation, Ea Energianalyse \& Risø DTU, Copenhagen. 